\title{
A LOCALLY MODIFIED SINGLE-PHASE MODEL FOR ANALYZING MAGNETOHYDRODYNAMIC BOUNDARY LAYER FLOW AND HEAT TRANSFER OF NANOFLUIDS OVER A NONLINEARLY STRETCHING SHEET WITH CHEMICAL REACTION
}

\author{
POORIA AKBARZADEH \\ School of Mechanical Engineering, Shahrood University of Technology, Shahrood, Iran \\ e-mail: akbarzad@ut.ac.ir; p.akbarzadeh@shahroodut.ac.ir
}

\begin{abstract}
The problem of boundary layer flow and heat transfer of nanofluids over nonlinear stretching of a flat sheet in the presence of a magnetic field and chemical reaction is investigated numerically. In this paper, a new locally modified single-phase model for the analysis is introduced. In this model, the effective viscosity, density and thermal conductivity of the solid-liquid mixtures (nanofluids) which are commonly utilized in the homogenous single-phase model, are locally combined with the prevalent single-phase model. Similarity transformation is used to convert the governing equations into three coupled nonlinear ordinary differential equations. These equations depend on five local functions of the nanoparticle volume fraction viz., local viscosity ratio, magnetic, Prandtl, Brownian motion and thermophoresis functions. The equations are solved using Newton's method and a block tridiagonal matrix solver. The results are compared to the prevalent single-phase model. In addition, the effect of important governing parameters on the velocity, temperature, volume fraction distribution and the heat and mass transfer rates are examined.
\end{abstract}

Keywords: nanofluid, magnetohydrodynamic, nonlinear stretching sheet, similarity transformation, locally modified single-phase model

\section{Introduction}

The enhancement of heat transfer in an industrial process such as cooling of electronic devices, guide or thrust bearings, high-speed sliding surfaces, strips or filaments, and etc., may create energy savings, reduce the process time, increase efficiency and lengthen the working life of equipment. Convective heat transfer can be improved by changing flow geometry, boundary conditions, or by enhancing thermal conductivity of the fluid (Wang and Mujumdar, 2007). One way to increase the thermal conductivity of base fluids is the use of nanoparticles (such as $\mathrm{Cu}, \mathrm{Ag}, \mathrm{Al}$, and etc. as metallic solid, $\mathrm{CuO}, \mathrm{Al}_{2} \mathrm{O}_{3}, \mathrm{TiO}_{2}$ and etc., as metallic oxide particles, multi walled nanotubes (MWNTs) and single wall nanotubes (SWNTs) (as metallic nanotubes) suspended in the fluids. Indeed, the Brownian motion of the nanoparticles in these suspensions is one of the potential contributors to this enhancement (Choi, 1995; Choi et al., 2001; Xie et al., 2003; Li and Peterson, 2007; Aminossadati and Ghasemi, 2009; Hamad and Ferddows, 2012). Apparently, Choi (1995) was the first researcher who introduced the term nanofluids to refer to the fluid with suspended nanoparticles, and up from this time, many researchers focused on numerical or experimental studies in the field of thermophysical and also heat and fluid flow properties of nanofluids such by Choi (1995), Choi et al. (2001), Xie et al. (2003), Li and Peterson (2007), Aminossadati and Ghasemi (2009), Hamad and Ferddows (2012), Wen and Ding Y. (2004), Heris et al. (2006), Abu-Nada and Chamkhac (2010), Sheikhzadeh et al. (2011) and to name but a few. 
As aforesaid, cooling of continuous strips or filaments by drawing them through a motionless fluid is one of the heat transfer processes in the industry. In these respects, the feature of the final product (e.g. plastic and polymer sheets manufactured by extrusion, glass-fiber and paper production, metal spinning, etc.) depends on the cooling rate and the process of stretching (Rana and Bhargava, 2012). Therefore, simulation of boundary layer behavior of fluid flow over the stretching surface (strips or filaments) can be useful for predicting heat transfer characteristics of such a process. The basic and elementary works on Boundary Layer Flow (BLF) over a continuous moving surface (with constant velocity) were reported by Sakiadis (1961a,b,c). After that, Crane (1970) published a report about the exact temperature distribution of the steady BLF of a viscous fluid caused by stretching a flat isothermal sheet (with a linearly variable velocity). The temperature and concentration distributions of BLF over an isothermal moving plate with blowing or suction were found by Gupta and Gupta (1977). The same problem was studied by Chen and Char (1988) in which the sheet was subjected to a prescribed temperature and heat flux.

The boundary layer and thermal characteristics of fluid flow over a nonlinear stretching sheet were examined for the first time by Vajravelu (2001). Then, Vajravelu and Cannon (2006) investigated the existence of a solution for the nonlinear problem by using the Schauder theory. Afterwards, Cortell (2007) analyzed flow and heat transfer over a nonlinear stretching sheet for the prescribed and constant surface temperature as boundary conditions. Prasad et al. (2010) presented a numerical solution for Magneto-Hydrodynamics (MHD) flow of an electrically conducting viscous fluid over a stretching sheet with variable fluid properties. They assumed that the stretching velocity and the transverse magnetic field varied as a power function of the distance from the origin. Postelnicu and Pop (2011) explored steady 2D laminar BLF of a non-Newtonian power-law fluid past a permeable non-linear stretching wedge. And recently, Vajravelu et al. (2014) published a paper on the subject of MHD flow and heat transfer of a non-Newtonian power-law fluid over an unsteady stretching isothermal sheet.

Since using nanofluids may improve heat transfer behavior of an engineering process, many researchers examined the effect of those fluids on the boundary layer and thermal characteristics of flow caused by stretching a surface. In this respect, Bachok et al. (2010) studied the steady BLF of nanofluids over a continuous moving surface (with constant velocity). Khan and Pop (2010) obtained the temperature distribution of steady BLF of nanofluids over a linear isothermal stretching flat sheet. Gorder et al. (2010) presented the similarity solution for the nano-BLFs over a linearly stretching sheet, in which on the surface sheet the velocity slip was assumed to be proportional to the local shear stress. Hassani et al. (2011) obtained an analytical solution for BLF of a nanofluid past a linearly stretching sheet using the homotopy analysis method (HAM). Rana and Bhargava (2012) studied numerically flow and heat transfer of a nanofluid over a nonlinearly stretching sheet. They used the finite difference, finite element, and variational method in their computations. Nadeem et al. (2014) analyzed flow of a three-dimensional water-based nanofluid over an exponentially stretching sheet. And recently, Das (2015) investigated the problem of BLF of a nanofluid over a non-linear permeable stretching sheet at a predestined surface temperature in the presence of partial slip.

The study of Magneto-Hydrodynamics (MHD) flow of an electrically conducting fluid due to a stretching sheet is important in modern engineering processes. Metallurgy, metalworking, metal fusion in an electrical furnace, and etc., are some examples of such processes (Ibrahim and Shanker, 2014). The MHD flow analysis over a stretching sheet with various aspects such as types of fluids, magnetic effect, stagnation geometry and the temperature effect can be seen in works of many researchers such as Ishak et al. (2008), Fadzilah et al. (2011), Mahapatra et al. (2009), Prasad et al. (2010), and to name but a few. Ibrahim et al. (2013) studied the MHD stagnation-point flow and heat transfer due to a nanofluid towards a stretching sheet using the Runge-Kutta fourth order numerical method. They analyzed the effect of the velocity 
ratio parameter on both the local Nusselt number and local Sherwood number. In the same year, Ibrahim and Shankar (2013) investigated MHD boundary layer flow and heat transfer of a nanofluid past a permeable stretching sheet with velocity, thermal and solutal slip boundary conditions. Recently, Ibrahim and Shankar (2014) studied MHD boundary layer flow and heat transfer of a nanofluid over a non-isothermal stretching sheet. Their analysis was done for two different cases, namely a prescribed surface temperature and prescribed heat flux.

The above mentioned literature review shows that in order to investigate the heat transfer characteristics of nanoparticles (or generally small solid particles) suspended in a fluid, two main approaches have been adopted by researchers. The first approach is the two-phase model which considers both the fluid phase and the solid particles behavior in the heat transfer process. The second one is the single-phase model in which both phases are in thermal and hydrodynamic equilibrium state (this approach is simpler and more computationally efficient). Generally in nanofluids, there are several factors that affect heat transfer enhancement. Some of the more important factors are Brownian motion (including diffusion, sedimentation, and dispersion), gravity, layering at the solid/liquid interface, particle clustering, friction between the fluid and the solid particles, etc. Therefore, in the absence of any experimental data and suitable theoretical studies, the existing macroscopic two-phase model has not enough precision for analyzing nanofluids. Consequently, the modified single-phase, considering some of the above factors, is more convenient than the two-phase model if the main interest of analysis is the heat transfer process (Khanafer et al., 2003). Therefore, in order to improve the results of the single-phase model for analyzing the nanofluids flow, some modifications are needed. In this paper, a new modified single-phase model for analyzing flow and heat transfer in nanofluids is introduced for the first time. In this model, all effective properties of nanofluids such as density, viscosity and thermal conductivity, which are normally used for the effective single-phase model (as constant values), are incorporated locally with the governing equations (as non-constant values). This approach is used for examining the BLF behavior and thermal characteristics of nanofluids flow over a nonlinear stretching sheet in the presence of a magnetic field and chemical reaction. The results for $\mathrm{Cu}$ and $\mathrm{Al}_{2} \mathrm{O}_{3}$ nanoparticles are compared to the prevalent single-phase model. This comparison depicts that the prevalent single-phase model has a considerable deviation for predicting the behavior of nanofluids flow, especially in dimensionless temperature and nanoparticle volume fraction. In addition, the effects of important governing parameters such as the transverse magnetic field, chemical reaction strength, thermophoresis parameter, nanoparticle volume fraction near the surface, etc., on the velocity, temperature, volume fraction distribution and dimensionless heat and mass transfer rates are examined.

\section{Mathematical governing equations}

The steady-state two-dimensional BLF of a nanofluid past a stretching sheet is considered with the nonlinear velocity $u_{w}=a_{u} x^{n}$, where $a_{u}$ is a positive constant, $n$ is the nonlinear stretching parameter and $x$ is the coordinate measured along the stretching surface, as shown in Fig. 1. Because of the impermeability characteristic of the sheet, the vertical velocity of the fluid on the surface is $v_{w}=0$. In this problem, the stretching surface is a non-isothermal face with the relation of $T_{w}(x)=T_{\infty}+a_{T} x^{r}$, where $a_{T}$ is a positive constant, $r$ is the surface temperature parameter in the prescribed surface temperature boundary condition and $T_{\infty}$ is the temperature of the fluid far away from the stretching sheet. In addition, the fluid is under a transverse magnetic field with strength $B(x)$ which is applied in the vertical direction, given by the special form of $B(x)=B_{0} x^{n-1}$, where $B_{0}$ is a positive constant. Also, it is assumed that the first-order homogeneous chemical reaction with the non-linear rate of $K=K_{0} x^{n-1}$ occurs in the fluid ( $K_{0}$ is the constant chemical reaction parameter). According to (Ibrahim and Shanker, 2014; 


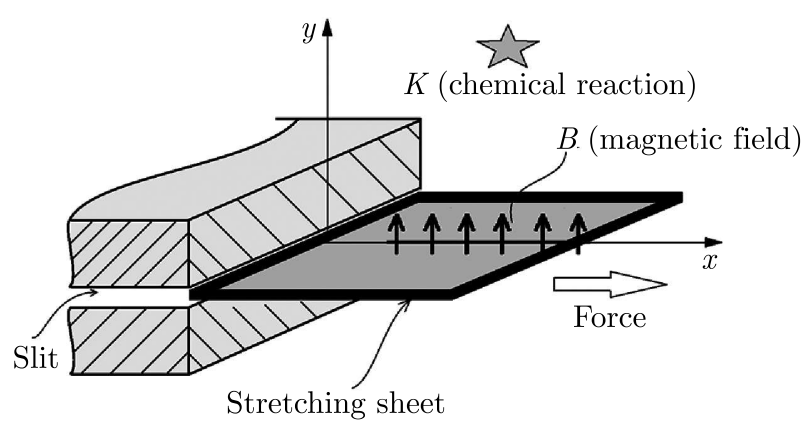

Fig. 1. Physical model of the stretching sheet and the coordinate system

Buongiorno, 2006; Yazdi et al., 2011), the following four governing equations of BLF include the continuity, momentum, energy, and nanoparticles concentration, respectively

$$
\begin{aligned}
& \frac{\partial u}{\partial x}+\frac{\partial v}{\partial y}=0 \quad u \frac{\partial u}{\partial x}+v \frac{\partial u}{\partial y}=\nu_{n f} \frac{\partial^{2} u}{\partial y^{2}}-\frac{\sigma B}{\rho_{n f}} u \\
& u \frac{\partial T}{\partial x}+v \frac{\partial T}{\partial y}=\alpha_{n f} \frac{\partial^{2} T}{\partial y^{2}}+\frac{(\rho c)_{p}}{(\rho c)_{n f}}\left[D_{B} \frac{\partial \varphi}{\partial y} \frac{\partial T}{\partial y}+\frac{D_{T}}{T_{\infty}}\left(\frac{\partial T}{\partial y}\right)^{2}\right] \\
& u \frac{\partial \varphi}{\partial x}+v \frac{\partial \varphi}{\partial y}=D_{B} \frac{\partial^{2} \varphi}{\partial y^{2}}+\frac{D_{T}}{T_{\infty}} \frac{\partial^{2} T}{\partial y^{2}}-K \varphi
\end{aligned}
$$

here, $T$ is temperature of the fluid, $u$ and $v$ are velocity components along the $x$ and $y$-axis respectively, $\varphi$ is the nanoparticle concentration (or volume fraction), $D_{T}$ is the thermophoretic diffusion coefficient, $D_{B}$ is the Brownian diffusion coefficient, $c$ is specific heat capacity, $\rho$ is density, $\alpha=k /(\rho c)$ is thermal diffusivity, $\nu$ is kinematic viscosity, $k$ is thermal conductivity, and $\sigma$ is electrical conductivity of the fluid. The subscripts $p$ and $n f$ refer to the nanoparticles and nanofluid, respectively. In this study, a new local Modified Single-Phase Model (here it is named as MSPM) for analyzing nanofluids flow and heat transfer is introduced. In this manner, the parameters $\nu_{n f}, k_{n f}, \rho_{n f}$, and $c_{n f}$ of the above governing equations may be introduced by the following four relations (Oztop and Abu-Nada, 2008)

$$
\begin{aligned}
& \frac{(\rho c)_{n f}}{(\rho c)_{f}}=1-\varphi+\varphi \frac{(\rho c)_{p}}{(\rho c)_{f}} \quad \frac{\rho_{n f}}{\rho_{f}}=1-\varphi+\varphi \frac{\rho_{p}}{\rho_{f}} \\
& \frac{\nu_{n f}}{\nu_{f}}=\frac{1}{(1-\varphi)^{2.5}\left(1-\varphi+\varphi \rho_{p} / \rho_{f}\right)} \quad \frac{k_{n f}}{k_{f}}=\frac{k_{p}+2 k_{f}-2 \varphi\left(k_{f}-k_{p}\right)}{k_{p}+2 k_{f}+\varphi\left(k_{f}-k_{p}\right)}
\end{aligned}
$$

where, the subscript $f$ refers to the base fluid. The associated boundary conditions for the problem are

$$
\begin{array}{lccc}
u(x, 0)=u_{w}(x)=a_{u} x^{n} & v(x, 0)=v_{w}(x)=0 & \\
T(x, 0)=T_{w}(x)=a_{T} x^{r}+T_{\infty} & \varphi(x, 0)=\varphi_{w} & \\
u(x, \infty)=0 \quad v(x, \infty)=0 & T(x, \infty)=T_{\infty} & \varphi(x, \infty)=\varphi_{\infty}
\end{array}
$$

where $\varphi_{w}$ and $\varphi_{\infty}$ are the nanoparticle volume fraction neighborhood to the surface and far away from the stretching sheet, respectively. By considering the following similarity transformations (Ibrahim and Shankar, 2013)

$$
\begin{array}{lc}
\eta=y \beta x^{\frac{n-1}{2}} & u=a_{u} x^{n} f^{\prime}(\eta) \quad v=-\gamma x^{\frac{n-1}{2}}\left(f+\frac{n-1}{n+1} \eta f^{\prime}\right) \\
\theta(\eta)=\frac{T-T_{\infty}}{T_{w}-T_{\infty}} & \psi(\eta)=\frac{\varphi-\varphi_{\infty}}{\varphi_{w}-\varphi_{\infty}}
\end{array}
$$


where, $\beta=\sqrt{a_{u}(n+1) /\left(2 \nu_{f}\right)}$ and $\gamma=\sqrt{a_{u} \nu_{f}(n+1) / 2}$, BLF governing equations (2.1) are transformed into three non-linear ordinary differential equations as follows

$$
\begin{aligned}
& f^{\prime \prime \prime}+F(\varphi)\left(f f^{\prime \prime}-\frac{2 n}{n+1} f^{\prime 2}\right)-G(\varphi) \frac{2}{n+1} f^{\prime}=0 \\
& \frac{1}{\operatorname{Pr}(\varphi)} \theta^{\prime \prime}+f \theta^{\prime}-\frac{2 r}{n+1} f^{\prime} \theta+N b(\varphi) \psi^{\prime} \theta^{\prime}+N t(\varphi) \theta^{\prime 2}=0 \\
& \psi^{\prime \prime}+\overline{\operatorname{Le}} f \psi^{\prime}+\frac{\overline{\mathrm{Nt}}}{\overline{\mathrm{Nb}}} \theta^{\prime \prime}-\frac{2 R}{n+1} \overline{\mathrm{Le}} \psi=0
\end{aligned}
$$

where $F(\varphi)$ is the local viscosity ratio function, $G(\varphi), \operatorname{Pr}(\varphi), N b(\varphi)$ and $N t(\varphi)$ are the local magnetic, local Prandtl, local Brownian and local thermophoresis functions are defined as

$$
\begin{aligned}
& F(\varphi)=(1-\varphi)^{2.5}\left(1-\varphi+\varphi \frac{\rho_{p}}{\rho_{f}}\right) \quad G(\varphi)=M(1-\varphi)^{2.5} \\
& N b(\varphi)=\frac{\overline{\mathrm{Nb}}}{1-\varphi+v p(\rho c)_{p} /(\rho c)_{f}} \quad N t(\varphi)=\frac{\overline{\mathrm{Nt}}}{1-\varphi+\varphi(\rho c)_{p} /(\rho c)_{f}} \\
& \operatorname{Pr}(\varphi)=\frac{\nu_{f}}{\alpha_{n f}}=\operatorname{Pr}_{f} \frac{k_{p} / k_{f}+2+2 \varphi\left(1-k_{p} / k_{f}\right)}{k_{p} / k_{f}+2-\varphi\left(1-k_{p} / k_{f}\right)}\left(1-\varphi+\varphi \frac{(\rho c)_{p}}{(\rho c)_{f}}\right)
\end{aligned}
$$

In the set of equations (2.6), $M=\sigma B_{0} /\left(a_{u} \rho_{f}\right)$ is the magnetic parameter, $\operatorname{Pr}_{f}=\nu_{f} / \alpha_{f}$ is the fluid Prandtl number, $\overline{\mathrm{Le}}=\nu_{f} / D_{B}$ is the Lewis number, $\overline{\mathrm{Nb}}=\left[(\rho c)_{p} D_{B}\left(\varphi_{w}-\varphi_{\infty}\right)\right] /\left[\nu_{f}(\rho c)_{f}\right]$ is the Brownian motion number, $\overline{\mathrm{Nt}}=\left[(\rho c)_{p} D_{T}\left(T_{w}-T_{\infty}\right)\right] /\left[T_{\infty} \nu_{f}(\rho c)_{f}\right]$ is the thermophoresis parameter and, finally, $R=K_{0} / a_{u}$. It is clear that $\overline{\mathrm{Nb}}$ is related to $\overline{\mathrm{Le}}$ as follows

$$
\overline{\mathrm{Nb}}=\frac{(\rho c)_{p}\left(\varphi_{w}-\varphi_{\infty}\right)}{\overline{\operatorname{Le}}(\rho c)_{f}}
$$

It should be noted that the enhancement of nanofluids thermal conductivity is because of four major mechanisms: (1) Brownian motion of nanoparticles, (2) nanolayer, (3) clustering, and (4) nature of heat transport in the nanoparticles. Also, some important parameters which affect the thermal conductivity of nanofluids are particle volume fraction, temperature, particles size and the size and property of the nanolayer. Therefore, a considerable number of studies can be found on the modelling of thermal conductivity of nanofluids, such as the Maxwell model, Hamilton-Crosser model, Bruggeman model, Wasp model, Maxwell-Garnett (MG) model, Gupta model, and to name but a few. However, there is a lack of reliable and comprehensive model which includes all mechanisms and influenced parameters for thermal conductivity of nanofluids (Esfe et al., 2014; Kumar et al., 2015). As a matter of fact, the present study does not focus on a comprehensive thermal conductivity model of nanofluids (so the Maxwell model (Eqs. (2.5) is selected as the model). The novelty of this study can be found in Eqs. (2.5) and (2.6). In Eqs. (2.5), $F(\varphi), \operatorname{Pr}(\varphi), N b(\varphi)$, and $N t(\varphi)$ are not constant during the calculation and they are updated locally based on the third relation of Eq. (2.5), which is more physical. It means that three relations of Eqs. (2.5) should be solved together. By considering Eqs. (2.3), non-linear ordinary differential equations (2.5) are solved subject to the following boundary conditions

$$
\begin{array}{llrl}
f^{\prime}(0)=1.0 & \theta(0)=1.0 & \psi(0)=1.0 & f(0)=0 \\
f^{\prime}(\infty)=0 & \theta(\infty)=0 & \psi(\infty)=0 &
\end{array}
$$

By introducing the local Reynolds number via $\operatorname{Re}_{x}=u_{w}(x) x / \nu_{f}=a_{u} x^{n+1} / \nu_{f}$, the surface heat flux through $q_{w}=k_{n f}(\partial T / \partial y)_{y=0}$, the surface mass flux via $q_{m}=D_{B}(\partial \varphi / \partial y)_{y=0}$, the local nanofluid Nusselt number through $\mathrm{Nu}_{n f}=x q_{w} /\left[k_{n f}\left(T_{w}-T_{\infty}\right)\right]$ and the local nanofluid 
Sherwood number by means of $\operatorname{Sh}_{n f}=x q_{m} /\left[D_{B}\left(\varphi_{w}-\varphi_{\infty}\right)\right]$, the following relation can be established

$$
\frac{\mathrm{Nu}_{n f}}{\sqrt{\mathrm{Re}_{x}}}=\sqrt{\frac{n+1}{2}}\left|\theta^{\prime}(0)\right| \quad \frac{\mathrm{Sh}_{n f}}{\sqrt{\mathrm{Re}_{x}}}=\sqrt{\frac{n+1}{2}}\left|\psi^{\prime}(0)\right|
$$

where $\mathrm{Nu}_{n f} / \sqrt{\mathrm{Re}_{x}}$ and $\mathrm{Sh}_{n f} / \sqrt{\mathrm{Re}_{x}}$ are known as dimensionless heat and mass transfer rates, respectively. Without loss of generality, one can assume that the nanoparticle volume fraction far away from the stretching sheet is zero or $\varphi_{\infty}=0$. In this paper, the fluid is a water based nanofluid containing different types of prevalent nanoparticles: copper $(\mathrm{Cu})$ and alumina $\left(\mathrm{Al}_{2} \mathrm{O}_{3}\right)$. Based on (Oztop and Abu-Nada, 2008), the thermophysical properties of the fluid (water) and the mentioned nanoparticles are given in Table 1.

Table 1. Thermophysical properties of the fluid (water) and three nanoparticles

\begin{tabular}{|l|c|c|c|}
\hline Properties & Fluid phase (water) & $\mathrm{Cu}$ & $\mathrm{Al}_{2} \mathrm{O}_{3}$ \\
\hline \hline$c[\mathrm{~J} / \mathrm{kgK}]$ & 4179 & 385 & 765 \\
\hline$\rho\left[\mathrm{kg} / \mathrm{m}^{3}\right]$ & 997.1 & 8933 & 3970 \\
\hline$k[\mathrm{~W} / \mathrm{mK}]$ & 0.613 & 400 & 40 \\
\hline $\mathrm{Pr}_{f}$ & 6.83 & - & - \\
\hline$(\rho c)_{p} /(\rho c)_{f}$ & - & 0.825 & 0.729 \\
\hline$k_{p} / k_{f}$ & - & 652.53 & 65.25 \\
\hline
\end{tabular}

\section{Algorithm of numerical solution}

The algorithm of numerical calculation (computer programming procedure) of non-linear differential equations (2.5)-(2.7) with boundary conditions (2.8) is given via items (i) to (viii). It should be noted that for step (ii), by assuming $\varphi_{\infty}=0$, the initial guess can be $\psi(\eta)=\varphi(\eta) / \varphi_{w}=\left[1-\exp \left(\eta-\eta_{\max }\right)\right] /\left[1-\exp \left(-\eta_{\max }\right)\right]$ as an example, where $\eta_{\max }$ is the maximum value of $\eta$ in the numerical calculation.

(i) Specify input data of the base fluid and nanoparticles: $\rho_{p} / \rho_{f},(\rho c)_{p} /(\rho c)_{f}, k_{p} / k_{f}, \operatorname{Pr}_{f}, \overline{\mathrm{Nb}}$, $\overline{\mathrm{Nt}}, \overline{\mathrm{Le}}, \varphi_{w}$

(ii) Set an initial guess for $\varphi(\eta)$ or its dimensionless parameter, i.e. $\psi(\eta)$

(iii) Calculate $F(\varphi), G(\varphi), N b(\varphi), N t(\varphi)$, and $\operatorname{Pr}(\varphi)$ based on step (i) and profile of $\varphi$

(iv) Solve the 1st relation of equation (2.5) to obtain $f(\eta)$ by using Newton's method

(v) Solve the 2nd relation of equation (2.5) to obtain $\theta(\eta)$ by using Newton's method

(vi) Solve the 3rd relation of equation (2.5) to update $\psi(\eta)$ or $\varphi(\eta)$ by using Newton's method

(vii) Check the error between the updated $\psi(\eta)$ and the guessed one

(viii) If the maximum error $\leqslant 10^{-5}$ then the procedure is finished; else go to step (iii)

\section{Validation of the numerical solution}

With reference to many studies such as Khan and Pop (2010), Das (2015), Ibrahim and Shankar (2013), Ibrahim and Shankar (2014) and etc., it is evident that the MSPM is reduced to the old Prevalent Single-Phase Model (PSPM) by considering the relations: $F(\varphi)=1.0, G(\varphi)=M$, $N b(\varphi)=\overline{\mathrm{Nb}}, N t(\varphi)=\overline{\mathrm{Nt}}$, and $\operatorname{Pr}(\varphi)=\operatorname{Pr}$. In order to check the validity of the present computational programming code, governing equations (2.5)-(2.7) subject to boundary conditions (2.8) are solved numerically for some values of the governing parameters of the PSPM. The results 
for the reduced Nusselt number $\left|\theta^{\prime}(0)\right|$ and the reduced Sherwood number $\left|\psi^{\prime}(0)\right|$ are compared with those obtained by Khan and Pop (2010) in Table 2. In this simulation, the default values of the parameters are considered as $\operatorname{Pr}=10, \overline{\mathrm{Le}}=10, n=1, r=0, M=0, R=0$ and $\eta_{\max }=20$. Also, Table 3 shows the comparison of the magnitude of the velocity gradient at the wall, $\left|f^{\prime \prime}(0)\right|$, between the present code results and that obtained previously by Fang et al. (2009) for the case of $n=1, \eta_{\max }=20$, and $M=0.25$-4.0. It can be seen from Tables 2 and 3 that the present results are in very good agreement with those reported by other researchers. Therefore, it is clear that the results obtained in this study are accurate.

Table 2. Comparison of $\left|\theta^{\prime}(0)\right|$ and $\left|\psi^{\prime}(0)\right|$ for $\operatorname{Pr}=10, \overline{\mathrm{Le}}=10, n=1, r=0, R=0, M=0$, $\eta_{\max }=20$

\begin{tabular}{|c|c|c|c|c|}
\hline \multirow{2}{*}{ Parameter } & \multicolumn{2}{|c|}{ Present result } & \multicolumn{2}{c|}{ Khan and Pop (2010) } \\
\cline { 2 - 5 } & $\left|\theta^{\prime}(0)\right|$ & $\left|\psi^{\prime}(0)\right|$ & $\left|\theta^{\prime}(0)\right|$ & $\left|\psi^{\prime}(0)\right|$ \\
\hline \hline$\overline{\mathrm{Nb}}=0.1, \overline{\mathrm{Nt}}=0.1$ & 0.95238 & 2.12939 & 0.9524 & 2.1294 \\
\hline$\overline{\mathrm{Nb}}=0.1, \overline{\mathrm{Nt}}=0.3$ & 0.52007 & 2.52863 & 0.5201 & 2.5286 \\
\hline$\overline{\mathrm{Nb}}=0.1, \overline{\mathrm{Nt}}=0.5$ & 0.32105 & 3.03514 & 0.3211 & 3.0351 \\
\hline$\overline{\mathrm{Nb}}=0.3, \overline{\mathrm{Nt}}=0.1$ & 0.25215 & 2.41002 & 0.2522 & 2.4100 \\
\hline$\overline{\mathrm{Nb}}=0.3, \overline{\mathrm{Nt}}=0.3$ & 0.13551 & 2.60882 & 0.1355 & 2.6088 \\
\hline$\overline{\mathrm{Nb}}=0.3, \overline{\mathrm{Nt}}=0.5$ & 0.08329 & 2.75187 & 0.0833 & 2.7519 \\
\hline$\overline{\mathrm{Nb}}=0.5, \overline{\mathrm{Nt}}=0.1$ & 0.05425 & 2.38357 & 0.0 .543 & 2.3836 \\
\hline$\overline{\mathrm{Nb}}=0.5, \overline{\mathrm{Nt}}=0.3$ & 0.02913 & 2.49837 & 0.0291 & 2.4984 \\
\hline$\overline{\mathrm{Nb}}=0.5, \overline{\mathrm{Nt}}=0.5$ & 0.01792 & 2.57310 & 0.0179 & 2.5731 \\
\hline
\end{tabular}

Table 3. Comparison of results for $\left|f^{\prime \prime}(0)\right|$ when $n=1$, and $\eta_{\max }=20$

\begin{tabular}{|l|c|c|}
\hline Parameter & $\begin{array}{c}\text { Present result } \\
\left|f^{\prime \prime}(0)\right|\end{array}$ & $\begin{array}{c}\text { Fang et al. (2009) } \\
\left|f^{\prime \prime}(0)\right|\end{array}$ \\
\hline \hline$M=0.25$ & 1.11803 & 1.1180 \\
\hline$M=4.0$ & 2.23606 & 2.2361 \\
\hline
\end{tabular}

\section{Results and discussion}

In this Section, the numerical results for profiles of dimensionless velocity $f^{\prime}(\eta)$, temperature $\theta(\eta)$, nanoparticle concentration $\psi(\eta)$, and etc., are presented for different values of the governing parameters. The obtained results are displayed through graphs in Figs. 2-7. For all simulations and their corresponding figures, the used governing parameters are given in Table 4 . It should be noted that the value of the Brownian motion number $\overline{\mathrm{Nb}}$ for the MSPM is calculated by equation (2.7), while for PSPM this is considered as the average of $\overline{\mathrm{Nb}}$ for $\mathrm{Cu}$ and $\mathrm{Al}_{2} \mathrm{O}_{3}$ nanoparticles. In order to compare the effect of using MSPM and PSPM on the results, the linear and non-linear stretching sheet problems for two different nanoparticles (i.e. $\mathrm{Cu}$ and $\mathrm{Al}_{2} \mathrm{O}_{3}$ ) are considered. These comparisons for six dimensionless profiles (i.e. $f, f^{\prime}, \theta, \theta^{\prime}, \psi$ and $\psi^{\prime}$ ) are presented in Fig. 2 (linear stretching sheet problem) and Fig. 3 (non-linear stretching sheet problem). The illustrated results in both Figs. 2 and 3 confirm that the temperature and nanoparticle volume fraction profiles (i.e. $\theta$ and $\psi$ ) converge quicker than the horizontal velocity profiles (i.e. $f^{\prime}$ ) for both PSPM and MSPM. Nevertheless, it is evident from the figures that the PSPM has a remarkable deviation for predicting the behavior of nanofluids flow, especially in dimensionless temperature $\theta$ and nanoparticle concentration $\psi$. Also, the comparison between the results presented in Figs. 2 and 3 displays that this deviation is intensified when the sheet is 
stretched nonlinearly. It should be noted that discussions about the PSPM and its effect on the results of the stretching sheet problem were recently reported in many studies such as Khan and Pop (2010), Hassani et al. (2011), Ibrahim and Shankar (2013), Ibrahim and Shanker (2014), and to name but a few. Therefore, for the next simulations, the MSPM is only considered. Also, based on the results shown in Figs. 2 and 3, one can observe that the boundary layer behavior and thermal characteristics of both nanoparticle flows are approximately the same. Hence, the further results and discussions are focused only on the $\mathrm{Cu}$-water nanofluid flow (using the MSPM).
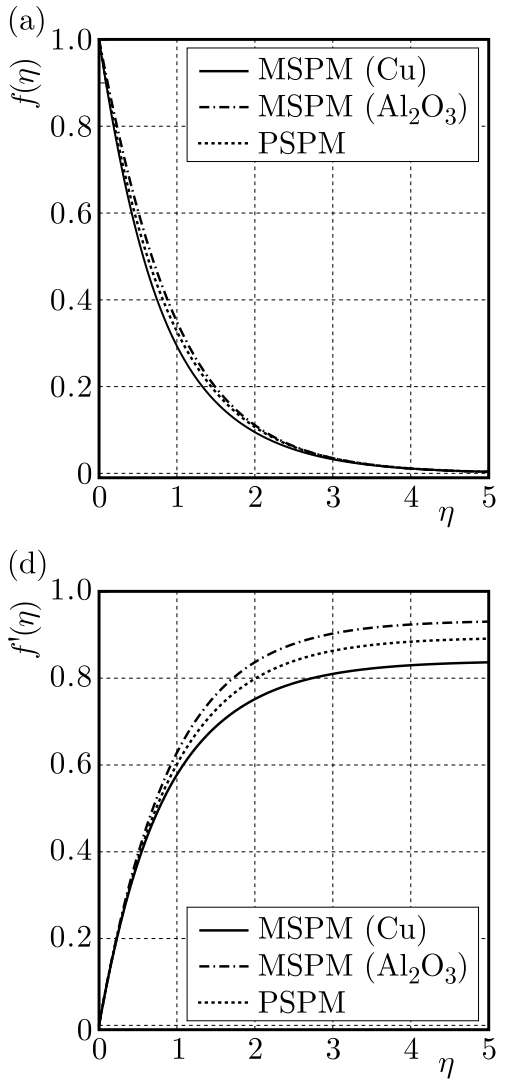

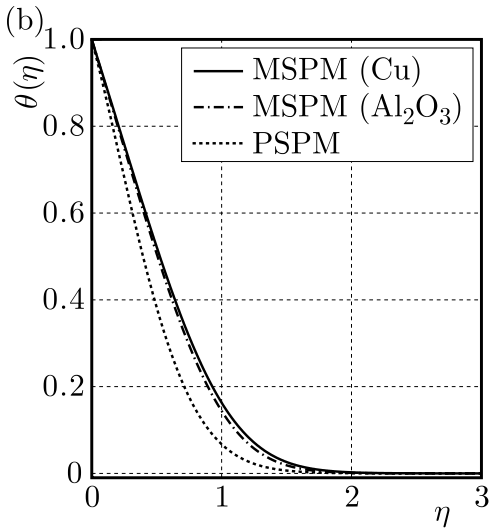

(e)

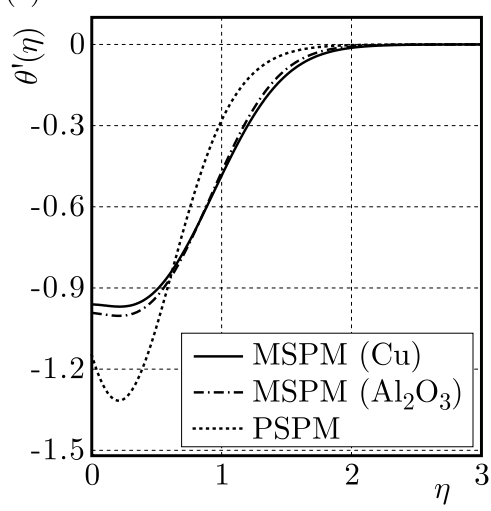

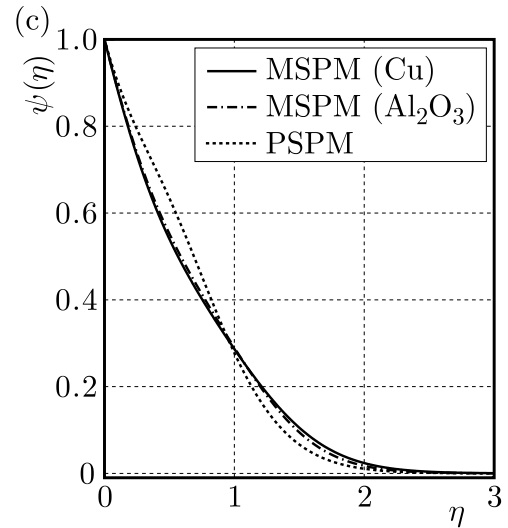

(f)

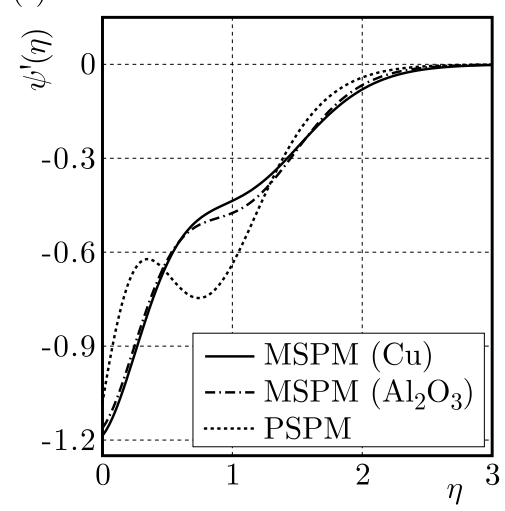

Fig. 2. Effect of the MSPM and PSPM on the dimensionless profiles for $n=1$ and $r=0$

Table 4. The governing parameters for nanofluid flow simulations

\begin{tabular}{|c|c|c|c|c|c|c|c|c|c|c|}
\hline Fig. & $n$ & & & & $\overline{\mathrm{Nt}}$ & $\overline{\mathrm{Le}}$ & $\varphi_{w}$ & $M$ & $R$ & \multicolumn{3}{|c|}{$\overline{\mathrm{Nb}}$} \\
\cline { 9 - 12 } & & & & & & & $\begin{array}{c}\mathrm{MSPM} \\
(\mathrm{Cu})\end{array}$ & $\begin{array}{c}\mathrm{MSPM} \\
\left(\mathrm{Al}_{2} \mathrm{O}_{3}\right)\end{array}$ & PSPM \\
\hline \hline 2 & 1 & 0 & 0.1 & 5 & 0.5 & 0.25 & 0.1 & 0.0825 & 0.0729 & 0.0777 \\
\hline 3 & 5 & 5 & 0.1 & 5 & 0.5 & 0.25 & 0.1 & 0.0825 & 0.0729 & 0.0777 \\
\hline 4 & 5 & 5 & 0.1 & 5 & 0.5 & $0.0-4.0$ & 0.1 & 0.0825 & - & - \\
\hline 5 & 5 & 5 & 0.1 & 5 & 0.5 & 2.0 & $0.0-10$ & 0.0825 & - & - \\
\hline 6 & 5 & 5 & 0.1 & 1 & $0.1-0.5$ & 2.0 & 5 & $0.0825-0.4125$ & - & - \\
\hline $7 \mathrm{a}$ & 5 & 5 & 0.1 & 5 & 0.5 & $0.0-4.0$ & 0.1 & 0.0825 & - & - \\
\hline $7 \mathrm{~b}$ & 5 & 5 & 0.1 & 5 & 0.5 & 2.0 & $0.0-10$ & 0.0825 & - & - \\
\hline $7 \mathrm{c}$ & 5 & 5 & 0.1 & 1 & $0.1-0.5$ & 2.0 & 5 & $0.0825-0.4125$ & - & - \\
\hline
\end{tabular}


(a)

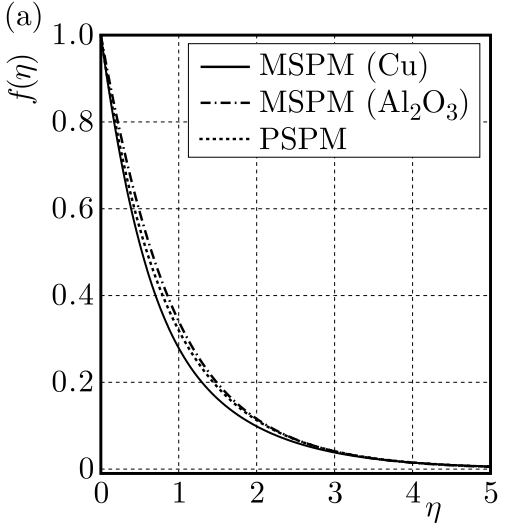

(d)

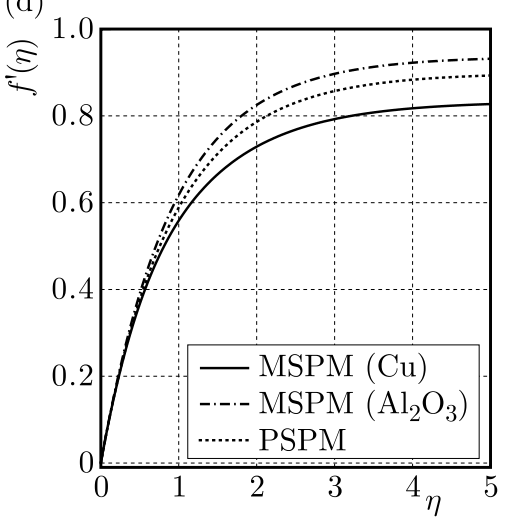

(b)

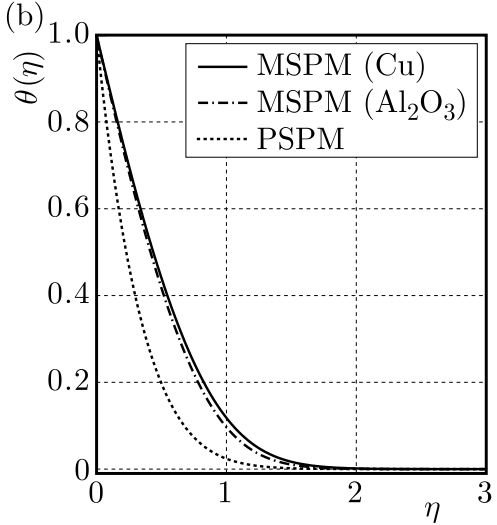

(e)

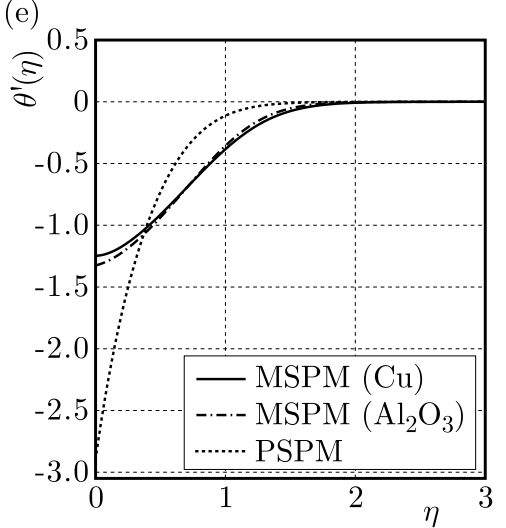

(c)

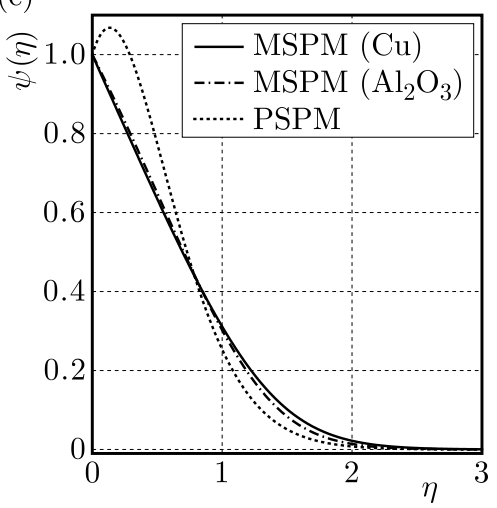

(f)

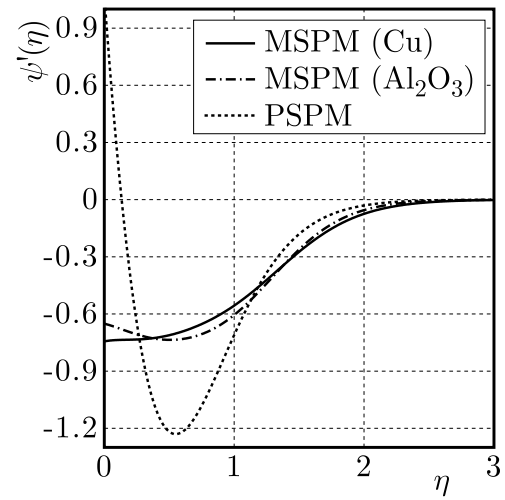

Fig. 3. Effect of the MSPM and PSPM on the dimensionless profiles for $n=5$ and $r=5$

(a)

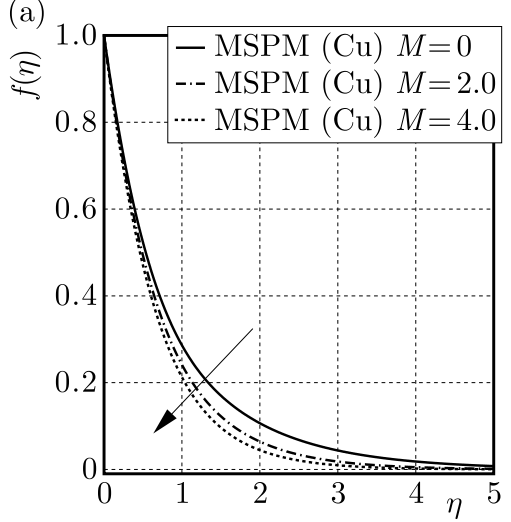

(b)

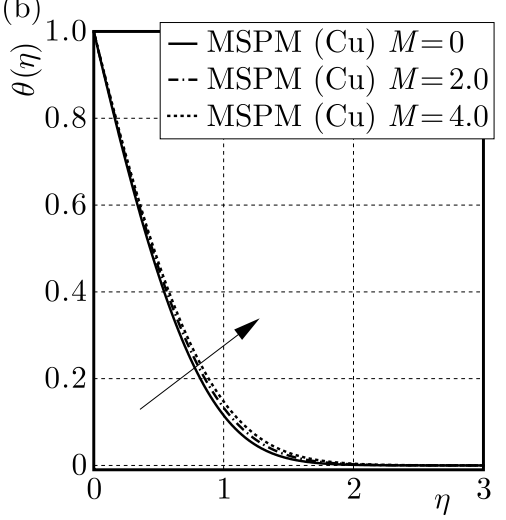

(c)

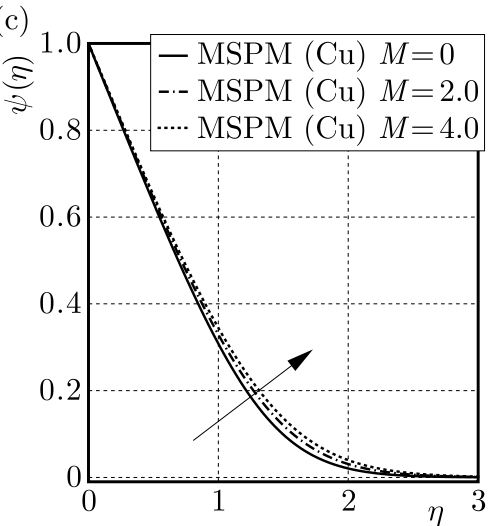

Fig. 4. Effect of $M$ on the dimensionless profiles for $n=5$ and $r=5$

The first analysis is related to the effects of the transverse magnetic field $M$ on the flow and thermal characteristics. By applying a transverse magnetic field, a Lorentz force is created, which results in a retarding force on the velocity of the flow (Ibrahim and Shanker, 2014). Therefore, as $M$ increases (and, consequently, increasing the retarding force), the velocity of the fluid decreases. This fact can be observed in Fig. 4a. In addition, Fig. 4b illustrates the impact of the transverse magnetic field on the temperature profile. The results show that as the magnetic parameter $M$ increases, the temperature profile and the thermal boundary layer thickness increase. Also, from Fig. 4c it is seen that the behavior of dimensionless concentration is the same as the temperature profile when the values of the magnetic parameter $M$ increase. 
Chemical reaction is an important process that should be considered in micro-mixing of biological systems such as cell-activation and protein-folding, particularly when the mixing of reactants for initiation is necessary. Lorentz forces produced by a magnetic field are able to move nano-liquids in a mixing process. Hence, one of the active methods of micro-mixing of biological samples is using a magnetic field in the presence of chemical reaction (Yazdi et al., 2011). Therefore, the second examination belongs to the effects of the chemical reaction strength $R$ on the nanofluids BLF characteristics. Figure 5 demonstrates the influence of the chemical reaction strength on the velocity, temperature and concentration graph. From Fig. 5a, it is evident that the values of $R$ has not any significant effect on the dimensionless velocity profile. But, by increasing the values of the chemical reaction parameter, the temperature gradient (Fig. 5b) and concentration gradient (Fig. 5c) on the wall intensify. In fact, for the case of the higher nanoparticle concentration gradient near the wall, the nanoparticle concentration decreases rapidly as $\eta$ increases. Therefore, the conductive heat transfer process is weakened.
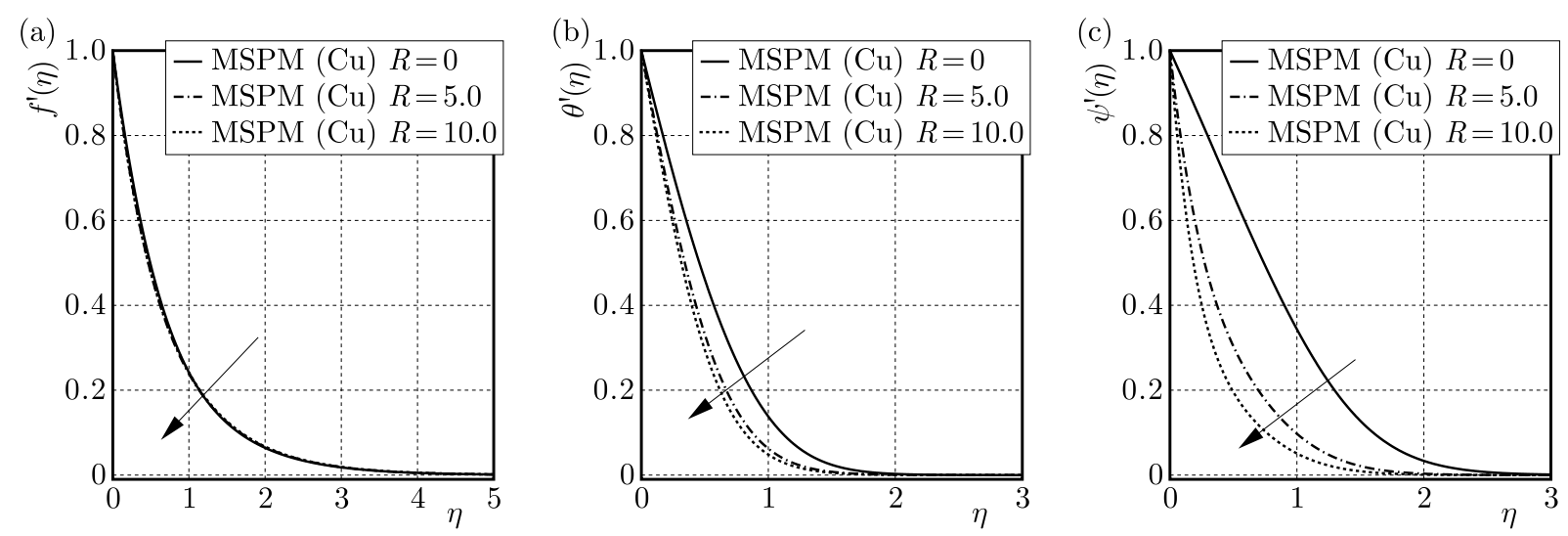

Fig. 5. Effect of $R$ on the dimensionless profiles for $n=5$ and $r=5$

As the MSPM depends on the value of the nanoparticle volume fraction near the surface $\varphi_{w}$, it is of great worth to investigate the effects of $\varphi_{w}$ on dynamic and thermal characteristics of the nanofluids flow. As it is predicted, when the value of the magnetic parameter $M$ does not change, variation of $\varphi_{w}$ has no significant influence on the velocity graph (see Fig. 6a). However, as it is noticed from Fig. 6b, increasing the nanoparticle volume fraction near the surface increases the thermal boundary layer thickness. And finally for Fig. 6c, since $\psi=\varphi / \varphi_{w}$, comparing the concentration graphs for various $\varphi_{w}$ has no any important consequence.
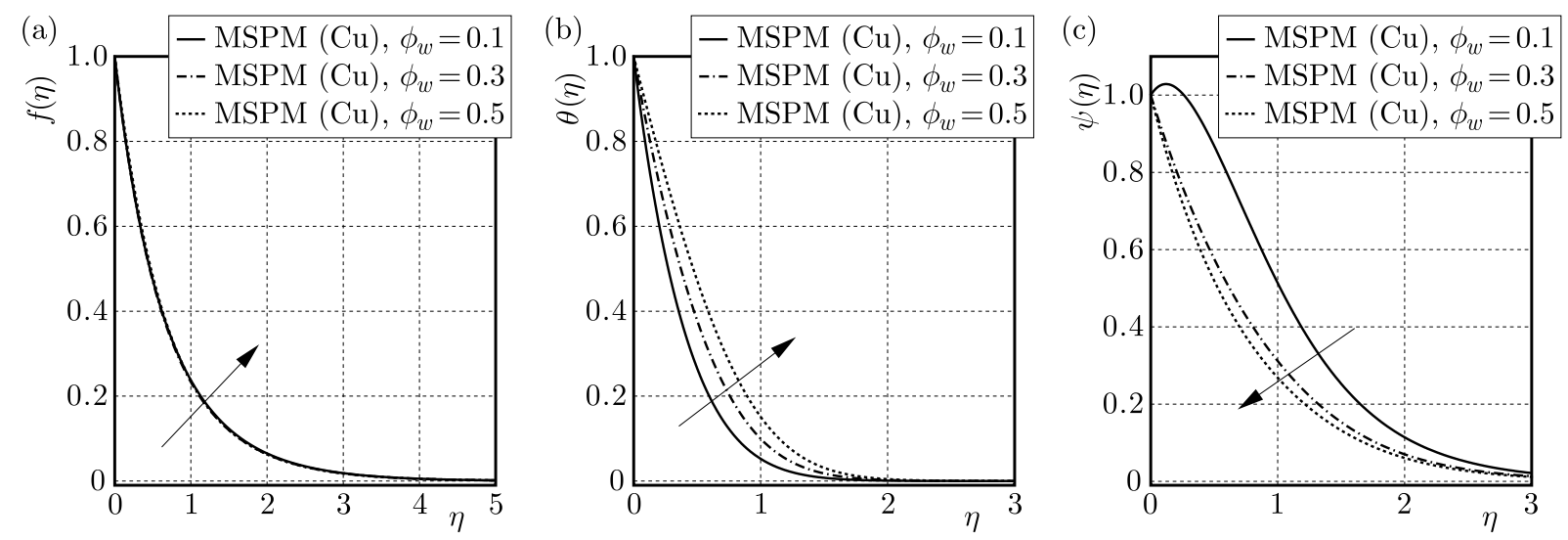

Fig. 6. Effect of $\varphi_{w}$ on the dimensionless profiles for $n=5$ and $r=5$ 
The last results are about the effect of $M, R$, and $\varphi_{w}$ on the dimensionless heat $\mathrm{Nu}_{n f} / \sqrt{\mathrm{Re}_{x}}$ and mass transfer rates $\mathrm{Sh}_{n f} / \sqrt{\mathrm{Re}_{x}}$ on the wall. This information is presented in Fig. 7. Figure 7a illustrates that the heat and mass transfer rates on the stretching wall decrease with an increase in the transverse magnetic field $M$. In fact, the magnetic field generates more heat in the boundary layer region and, hence, this reduces the wall heat transfer rate. Figure $7 \mathrm{~b}$ depicts that the wall mass transfer rate and the wall heat transfer rate increase with an increase in the chemical reaction parameter $R$. In addition, a decrease in the dimensionless heat transfer and an increase in the dimensionless mass transfer on the wall are observed with an increase in $\varphi_{w}$. These are shown in Fig. 7c.

(a)

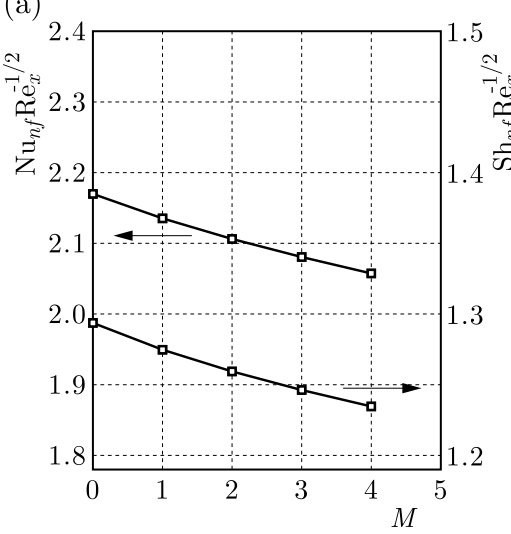

(b)

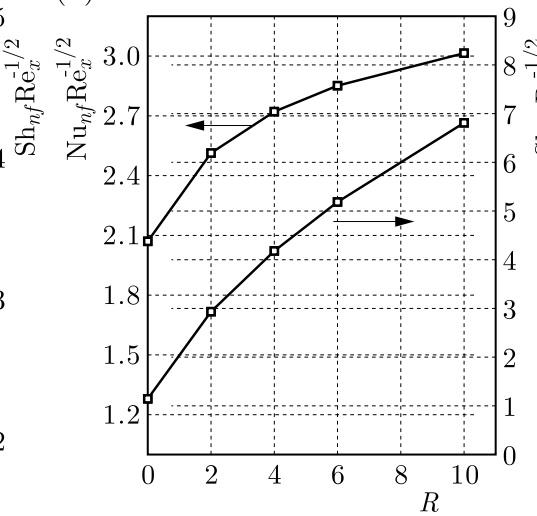

(c)

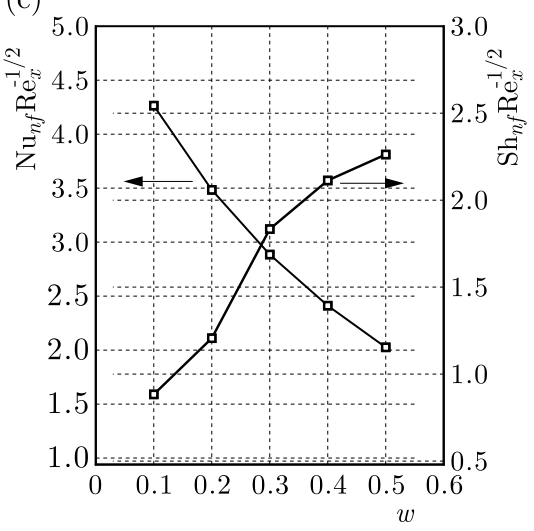

Fig. 7. Effect of $M, R$, and $\varphi_{w}$ on the dimensionless heat and mass transfer rates for $n=5$ and $r=5$

\section{Conclusion}

The problem of boundary layer flow and heat transfer of nanofluids over a nonlinear stretching sheet in the presence of a magnetic field and chemical reaction is examined numerically. In this study, a modified single-phase model for analyzing nanofluids flow and heat transfer is initiated. In this modified model, the effective density and viscosity of nanofluids and the effective thermal conductivity of the solid-liquid mixture which are prevalently used in the effective singlephase model (as constant values) are incorporated locally with the governing equations (as noconstant values). A similarity solution is proposed which depends on the local Prandtl number, local Brownian motion number, local Lewis number and the local thermophoresis number. The results for $\mathrm{Cu}$ and $\mathrm{Al}_{2} \mathrm{O}_{3}$ nanoparticles are compared to the prevalent single-phase model. This comparison shows that the prevalent single-phase model has a noticeable deviation for predicting the behavior of the nanofluids flow, especially in dimensionless temperature and nanoparticle volume fraction. In addition, the results exhibit that the heat and mass transfer rates on the stretching surface decrease with increase in the transverse magnetic field. Also, the wall mass transfer rate and the wall heat transfer rate increase with an increase in the chemical reaction parameter.

\section{Acknowledgments}

The author would like to acknowledge the Shahrood University of Technology which supported this project.

\section{References}

1. Abu-Nada E., Chamkhac A.J., 2010, Mixed convection flow in a lid-driven inclined square enclosure filled with a nanofluid, European Journal of Mechanics B/Fluids, 29, 472-482 
2. Aminossadati S.M., Ghasemi B., 2009, Natural convection cooling of a localised heat source at the bottom of a nanofluid-filled enclosure, European Journal of Mechanics B/Fluids, 28, 630-640

3. BACHOK N., Ishak A., Pop, I., 2010, Boundary-layer flow of nanofluids over a moving surface in a flowing fluid, International Journal of Thermal Sciences, 49, 1663-1668

4. Buongiorno J., 2006, Convective transport in nanofluids, ASME Journal of Heat Transfer, 128, 240-250

5. Chen C.K., Char M. I., 1988, Heat transfer of a continuous stretching surface with suction or blowing, Journal Mathematical Analysis and Applications, 135, 568-580

6. CHor S.U.S., 1995, Enhancing thermal conductivity of fluids with nanoparticles, ASME Fluids Engineering Division, 231, 99-105

7. Choi S.U.S., Zhang Z.G., Yu W., Lockwood F.E., Grulke E.A., 2001, Anomalous thermal conductivity enhancement in nanotube suspensions, Applied Physics Letters, 79, 14, 2252-2254

8. Cortell R., 2007, Viscous flow and heat transfer over a nonlinearly stretching sheet, Applied Mathematics and Computation, 184, 864-873

9. CRAne L.J., 1970, Flow past a stretching plate, Kurze Mitteilungen-Brief Reports-Communications Breves, 21, 645-647

10. DAs K., 2015, Nanofluid flow over a non-linear permeable stretching sheet with partial slip, Journal of the Egyptian Mathematical Society, 23, 2, 451-456

11. Esfe M.H., Saedodin S., Mahian O., Wongwises S., 2014, Thermal conductivity of $\mathrm{Al}_{2} \mathrm{O}_{3}$ /water nanofluids - Measurement, correlation, sensitivity analysis, and comparisons with literature reports, Journal of Thermal Analysis and Calorimetry, 117, 2, 675-681

12. Fadzilah M., Nazar R., Norihan M., Pop I., 2011, MHD boundary-layer flow and heat transfer over a stretching sheet with induced magnetic field, Journal of Heat and Mass Transfer, 47, 155-162

13. Fang T., Zhang J., Yao S., 2009, Slip MHD viscous flow over a stretching sheet - An exact solution, Communications in Nonlinear Science and Numerical Simulation, 14, 3731-3737

14. Gorder R.A.V., Sweet E., Vajravelu K., 2010, Nano boundary layers over stretching surfaces, Communications in Nonlinear Science and Numerical Simulation, 15, 1494-1500

15. Gupta P.S., Gupta A.S., 1977, Heat and mass transfer on a stretching sheet with suction or blowing, The Canadian Journal of Chemical Engineering, 55, 744-746

16. Hamad M.A.A., Ferddows M., 2012, Similarity solutions to viscous flow and heat transfer of nanofluid over nonlinearly stretching sheet, Applied Mathematics and Mechanics (English Edition), 33, 7, 923-930

17. Hassani M., Mohammad Tabar Nemati H., Domairry G., Noori F., 2011, An analytical solution for boundary layer flow of a nanofluid past a stretching sheet, International Journal of Thermal Sciences, 50, 2256-2263

18. Heris S.Z., Etemad S.G., Esfahany M.N., 2006, Experimental investigation of oxide nanofluids laminar flow convective heat transfer, International Communications in Heat and Mass Transfer, 33, 529-535

19. Ibrahim W., ShankAR B., 2013, MHD boundary layer flow and heat transfer of a nanofluid past a permeable stretching sheet with velocity, thermal and solutal slip boundary conditions, Computer and Fluids, 75, 1-10

20. Ibrahim W., Shankar B., Nandeppanavar M.M., 2013, MHD stagnation point flow and heat transfer due to nanofluid towards a stretching sheet, International Journal of Heat and Mass Transfer, 56, 1-9

21. Ibrahim W., Shanker B., 2014, Magnetohydrodynamic boundary layer flow and heat transfer of a nanofluid over non-isothermal stretching sheet, ASME Journal of Heat Transfer, 136, 051701-9 
22. Ishak A., Nazar R., Pop, I., 2008, Hydro magnetic flow and heat transfer adjacent to a stretching vertical sheet, Journal of Heat and Mass Transfer, 44, 921-927

23. Khan W.A., Pop I., 2010, Boundary-layer flow of a nanofluid past a stretching sheet, International Journal of Heat and Mass Transfer, 53, 2477-2483

24. Khanafer K., Vafai K., Lightstone M., 2003, Buoyancy-driven heat transfer enhancement in a two-dimensional enclosure utilizing nanofluids, International Journal of Heat and Mass Transfer, 46, 3639-3653

25. Kumar P.M., Kumar J., Tamilarasan R., Sendhilnathan S., Suresh S., 2015, Review on nanofluids theoretical thermal conductivity models, Engineering Journal, 19, 1, 67-83

26. Li C.H., Peterson G.P., 2007, Mixing effect on the enhancement of the effective thermal conductivity of nanoparticle suspensions (nanofluids), International Journal of Heat and Mass Transfer, 50, 4668-4677

27. Mahapatra T.R., Nandy S.K., Gupta A.S., 2009, Magnetohydrodynamic stagnation point flow of a power-law fluid towards a stretching sheet, International Journal of Non-Linear Mechanics, 44, 124-129

28. NADeEm S., HaQ R.U., Khan Z.H., 2014, Heat transfer analysis of water-based nanofluid over an exponentially stretching sheet, Alexandria Engineering Journal, 53, 219-224

29. Oztop H.F., Abu-Nada E., 2008, Numerical study of natural convection in partially heated rectangular enclosures filled with nanofluids, International Journal of Heat and Fluid Flow, 29, 1326-1336

30. Postelnicu A., Pop I., 2011, Falkner-Skan boundary layer flow of a power-law fluid past a stretching wedge, Applied Mathematics and Computation, 217, 4359-4368

31. Prasad K.V., Vajravelu K., Datti P.S., 2010, Mixed convection heat transfer over a non-linear stretching surface with variable fluid properties, International Journal of Non-Linear Mechanics, 45, 320-330

32. Rana P., Bhargava R., 2012, Flow and heat transfer of a nanofluid over a nonlinearly stretching sheet: A numerical study, Communications in Nonlinear Science and Numerical Simulation, 17, 212-226

33. SAKiAdis B.C., 1961a, Boundary layer behavior on continuous moving solid surfaces. I. Boundary layer equations for two-dimensional and axis-symmetric flow, American Institute of Chemical Engineer Journal, 7, 1, 26-28

34. SAKiAdis B.C., 1961b, Boundary layer behavior on continuous moving solid surfaces. II. Boundary layer on a continuous flat surface, American Institute of Chemical Engineer Journal, 7, 2, 221-225

35. SAKIADIS B.C., 1961c, Boundary layer behavior on continuous moving solid surfaces. III. Boundary layer on a continuous cylindrical surface, American Institute of Chemical Engineer Journal, 7, 3, 467-472

36. Sheikhzadeh G.A., Arefmanesh A., Kheirkhah M.H., Abdollahi R., 2011, Natural convection of $\mathrm{Cu}$-water nanofluid in a cavity with partially active side walls, European Journal of Mechanics B/Fluids, 30, 2, 166-176

37. Vajravelu K., 2001, Viscous flow over a nonlinearly stretching sheet, Applied Mathematics and Computation, 124, 281-288

38. Vajravelu K., Cannon J.R., 2006, Fluid flow over a nonlinearly stretching sheet, Applied Mathematics and Computation, 181, 609-618

39. Vajravelu K., Prasad K.V., Datti P.S., Raju B.T., 2014, MHD flow and heat transfer of an Ostwald-de Waele fluid over an unsteady stretching surface, Ain Shams Engineering Journal, 5, 157-167

40. Wang X.Q., Mujumdar A.S., 2007, Heat transfer characteristics of nanofluids: a review, International Journal of Thermal Sciences, 46, 1-19 
41. Wen D., Ding Y., 2004, Experimental investigation into convective heat transfer of nanofluids at the entrance region under laminar flow conditions, International Journal of Heat and Mass Transfer, 47, 5181-5188

42. Xie H.Q., Lee H., Youn W., Choi M., 2003, Nanofluids containing multiwalled carbon nanotubes and their enhanced thermal conductivities, Journal of Applied Physics, 94, 8, 4967-4971

43. Yazdi M.H., Abdullah S., Hashim I., Sopian K., 2011, Slip MHD liquid flow and heat transfer over non-linear permeable stretching surface with chemical reaction, International Journal of Heat and Mass Transfer, 54, 3214-3225

Manuscript received May 15, 2017; accepted for print July 25, 2017 